\title{
Índice de eficiência de macronutrientes em espécies arbóreas - floresta ombrófila mista montana/Paraná
}

\section{Index of efficiency of macronutrients in tree species in a mixed araucaria forest/Paraná State}

\author{
Marcos Vinicius Winckler ${ }^{1}$; Renato Marques²; \\ Ronaldo Viana Soares ${ }^{3}$; Luciano Farinha Watzlawick ${ }^{4 *}$
}

\section{Resumo}

O trabalho aqui apresentado teve como objetivo principal caracterizar o Índice de Eficiência de Macronutrientes $\left(\mathrm{IEM}_{\text {acronutrientes }}=\right.$ Biomassa Produzida/Nutriente Utilizado) nos componentes da biomassa acima do solo (DAP $\left.{ }^{3} 10,0 \mathrm{~cm}\right)$ das espécies arbóreas da Floresta Ombrofila Mista Montana, General Carneiro/PR, utilizando 20 unidades amostrais primárias (UAPs) de $12 \mathrm{~m}$ x $12 \mathrm{~m}$. Os índices de eficiência

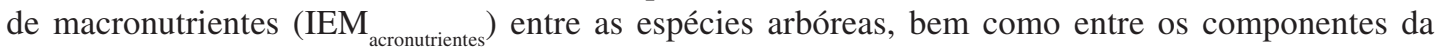
biomassa acima do solo (fuste $=$ madeira do fuste + casca; folhas e total $=$ fuste + galhos + folhas)

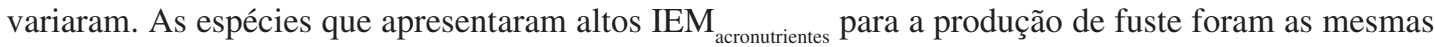

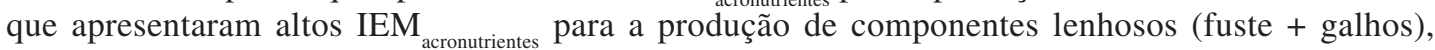
exceto Myrsine ferruginea; Schinus terebinthifolius e Calyptranthes concinna.

Palavras-chave: Espécies arbóreas. Eficiência de nutrientes. Floresta com Araucária.

\begin{abstract}
The main objective of this research work was to study the Efficiency Index of Macronutrients in tree biomass in a Mixed Araucaria Forest through 20 primary sample plots of $12 \mathrm{~m} \mathrm{x} 12 \mathrm{~m}$. The efficiency indexes of macronutrients $\left(\mathrm{EIM}_{\text {acronutrients }}\right)$ varied between the tree species, and between the biomass up ground components (stem $=$ wood stem + bark; leaves and total $=$ stem + branch + leaves $)$. The species that showed hight EIM acronutrients $_{\text {to the stem production were the same that showed hight EIM acronutrients }}$ to the woody components production (stem + branches), excetp Myrsine ferruginea; Schinus terebinthifolius and Calyptranthes concinna.
\end{abstract}

Key words: Tree species. Nutrients efficiency. Araucaria Forest.

1 Prof $^{\circ}$ Dr. do Departamento de Eng. Florestal/Centro de Ciências Tecnológicas/FURB - Universidade Regional de Blumenau.

Campus II, Centro de Ciências Tecnológicas, Depto de Engenharia florestal. E-mail: caldeira@ furb.br

2 Prof $^{\circ}$ Dr. do Depto de Solos e Engenharia Agrícola - UFPR. E-mail: marques@ufpr.br

3 Prof ${ }^{\mathrm{o}}$ Tiular do Depto de Ciências Florestais da Universidade Federal do Paraná. rvsoares@ floresta.ufpr.br

4 Prof $^{\circ}$ Dr. Do Depto de Engenharia Ambiental da Universidade Estadual do Centro-Oeste - UNICENTRO. BR 153, Km 7, Bairro

Riozinho, 84.500-000 - Irati/PR. E-mail: farinha@irati.unicentro.br

* Autor para correspondência 


\section{Introdução}

Do ponto de vista nutricional, uma espécie/ genótipo superior é aquela capaz de desenvolver e ter uma boa produção em condições desfavoráveis de fertilidade do solo, tendo habilidade de absorver os nutrientes necessários, em menor quantidade, e/ ou, distribuí-los de uma maneira mais eficiente nos diversos componentes da planta, sem comprometer a produtividade (FURLANI et al., 1984).

A maior ou menor eficiência de uso de nutrientes (SCHUMACHER, 1995) das diferentes espécies arbóreas pode ser o reflexo de uma adaptação às perdas anuais e ao aumento da reutilização dos mesmos. No entanto, uma menor devolução de serapilheira, principalmente de folhas, e o alto índice de redistribuição de alguns nutrientes antes da queda das folhas são estratégias que as espécies podem utilizar para aumentar a conservação de nutrientes nos componentes das árvores.

$\mathrm{Na}$ maioria das vezes, nas florestas tropicais, a eficiência de utilização de determinados nutrientes é considerada baixa. Nestas florestas as condições climáticas propiciam uma alta produção de biomassa e uma grande circulação de nutrientes através da lixiviação e da serapilheira depositada (SCHUMACHER, 1995).

A eficiência de utilização de nutrientes varia em função da idade das espécies (PEREIRA et al., 1984; SCHUMACHER, 1995). Segundo Negi e Sharma (1984) árvores de Eucalyptus globulus com 5 anos de idade possuem uma tendência de apresentar uma menor eficiência do que árvores com 9 anos de idade. A eficiência varia também em função da espécie, sítio, procedências, estágios sucessionais e em plantações puras e consorciadas (GONÇALVES et al., 1992; CALDEIRA; RODON NETO; SCHUMACHER, 2002; CALDEIRA; RODON NETO; SCHUMACHER, 2004).

Neste estudo, deu-se ênfase somente aos aspectos relacionados com a eficiente na translocação de nutrientes. Entretanto, face à relevância do assunto para as espécies florestais, o mesmo precisa ser aprimorado, visando dominar e aprimorar, o conhecimento das estratégias de estabelecimento usado pelas espécies arbóreas no que diz respeito à eficiência de absorção, translocação e utilização de nutrientes.

O trabalho teve como objetivo caracterizar o índice de eficiência de macronutrientes (IEM $\left._{\text {acronutrientes }}\right)$ nos componentes da biomassa acima do solo (DAP ${ }^{3}$ 10,0 cm) das espécies arbóreas da Floresta Ombrófila Mista Montana, General Carneiro/ PR.

\section{Material e Métodos}

O estudo foi realizado em uma propriedade das Indústrias Pedro N. Pizzatto, localizada no município de General Carneiro, Paraná. General Carneiro está localizado nas coordenadas De acordo com Hansen e Baker (1979) a eficiência de utilização de nutrientes em uma determinada espécie vegetal pode ser definida como a quantidade de matéria seca em $\mathrm{kg}$ produzida por $\mathrm{kg}$ de nutriente utilizado. Através deste parâmetro pode-se analisar o quanto de matéria seca em uma determinada espécie vegetal foi produzido por kg de nutriente (PEREIRA et al., 1984).

A quantidade de matéria seca em $\mathrm{kg}$ de uma determinada espécie produzida por $\mathrm{kg}$ de nutriente utilizado pode ter outras denominações tais como eficiência nutricional (GONÇALVES et al., 1992), e índice de eficiência de utilização de nutrientes (DRUMOND; POGGIANI, 1993; LIMA, 1993; DRUMOND et al., 1997).

Espécies eficientes no uso de nutrientes são aquelas que apresentam capacidade em absorvê-los da rizosfera, incorporá-los e utilizá-los para a produção de biomassa acima e/ou baixo do solo. Determinada espécie pode ser eficiente dentro de três critérios: a) ser eficiente na absorção de nutrientes - baseado na capacidade da raiz em retirar os nutrientes do solo; b) ser eficiente na translocação de nutrientes - baseados na capacidade de produzir 


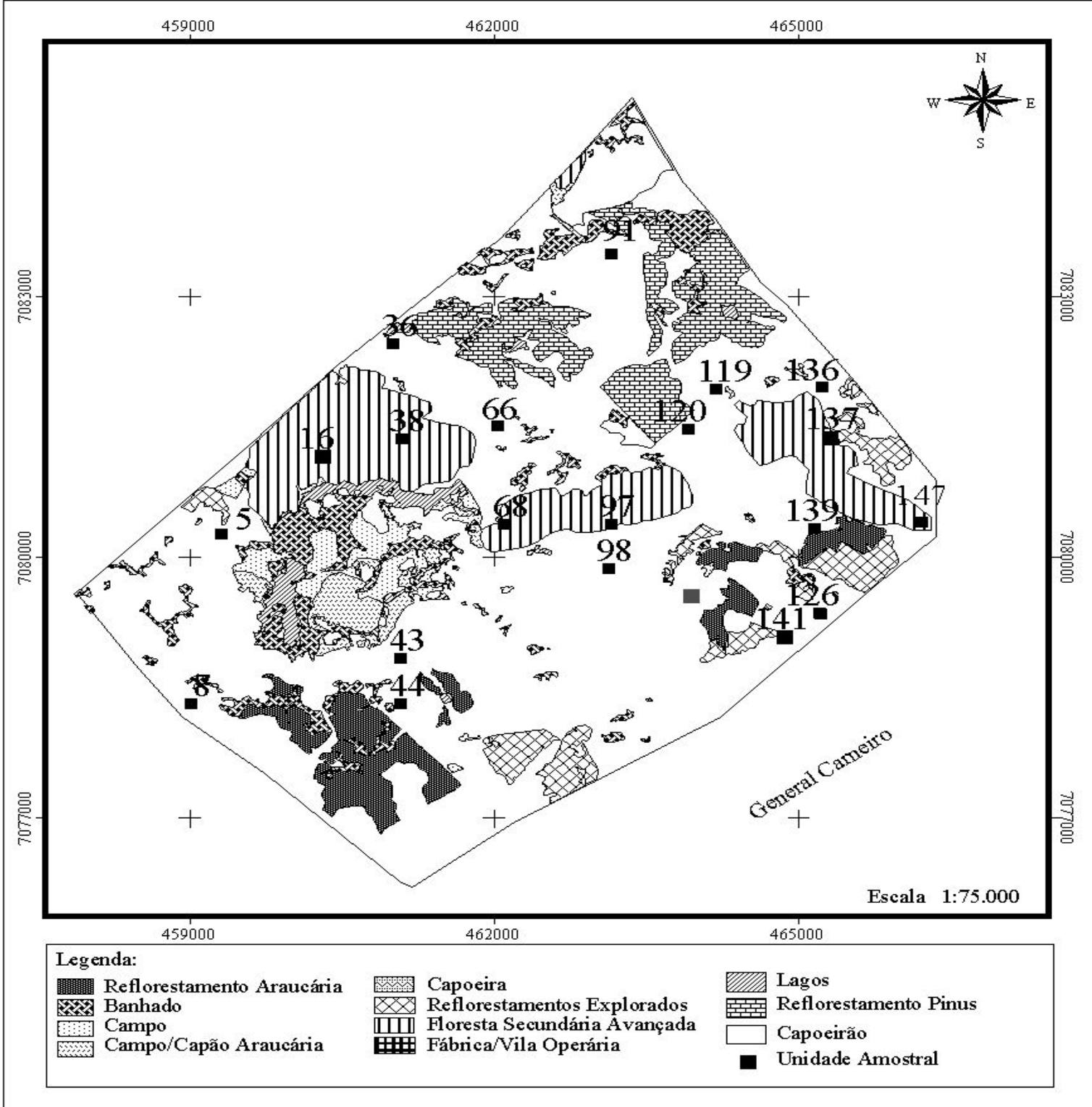

Figura 1. Uso do uso do solo e localização das unidades amostrais (UAs) na Floresta Ombrófila Mista Montana. 


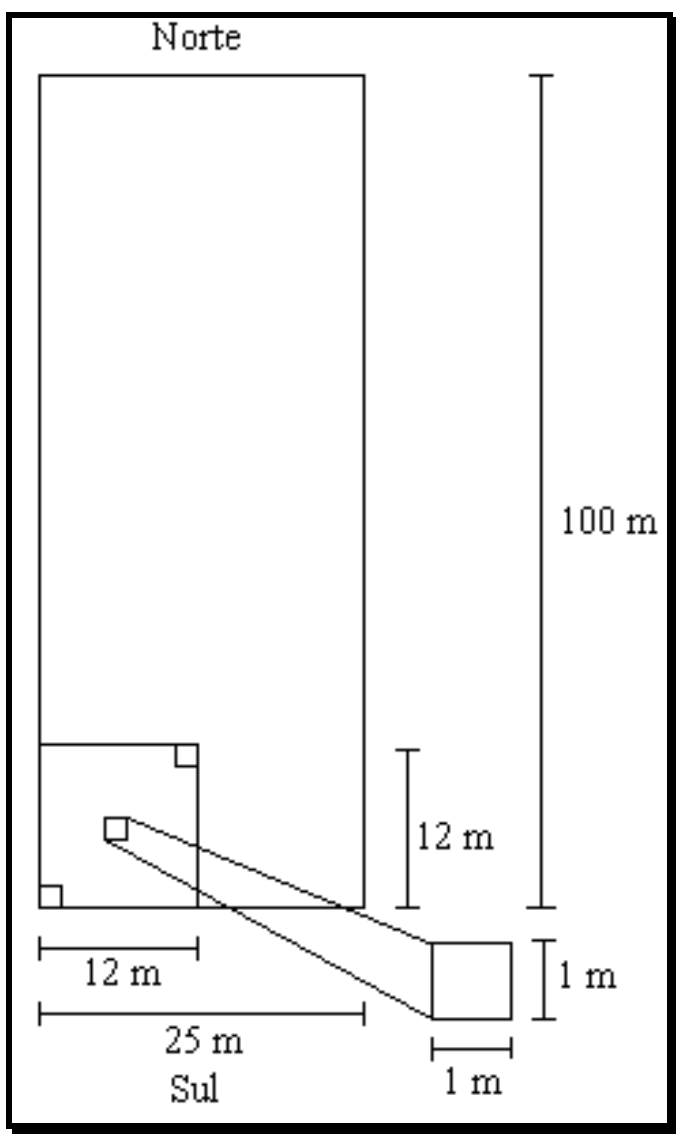

Figura 2. Esquema da instalação das unidades amostrais.

biomassa acima do solo e c) serem eficiente na utilização de nutrientes - baseado na capacidade de produzir biomassa acima do solo e abaixo do solo (BLAIR, 1993).

A seleção de material genético que melhor se adapte à condição de baixa fertilidade do solo tem sido uma preocupação constante, sendo desejáveis espécies, com maior capacidade de absorver e utilizar os nutrientes (MORAIS et al., 1990). A avaliação da eficiência de utilização de nutrientes por parte da diferentes espécies florestais, procedências e/ou clones é um parâmetro para auxiliar o silvicultor no momento de optar pelo material a ser utilizado nos reflorestamentos (CALDEIRA; RODON NETO; SCHUMACHER, 2002; CALDEIRA; RODON NETO; SCHUMACHER, 2004) geográficas $26^{\circ} 43^{\prime}$ 00 latitude $\mathrm{S}$ e 51 ${ }^{\circ} 24^{\prime} 35$ longitude W de Greenwich, com altitude aproximada de 1000 m s.n.m. (PARANÁ, 1987). A área da fazenda onde foi desenvolvido o trabalho é de aproximadamente de 4.570 ha.

Pela classificação de Köeppen, o clima da região é caracterizado como Subtropical Úmido Mesotérmico ( $\mathrm{Cfb}$ ), ou seja, temperado com verões frescos e invernos com ocorrência de geadas severas, sem estação seca. A média das temperaturas do mês mais quente é inferior a $22^{\circ} \mathrm{C}$ e a do mês mais frio é superior a $-18^{\circ} \mathrm{C}$ (PARANÁ, 1987; INSTITUTO AGRONÔMICO DO PARANÁ, 1994). Para Camargo (1998) o clima da região pode ser considerado como Temperado Semi-Úmido de Altitude.

Em relação ao relevo General Carneiro apresenta $20 \%$ de topografia plana, $65 \%$ de topografia ondulada e $15 \%$ de topografia montanhosa. Nesta região, as ordens de solos predominantes são os Neossolos Litólicos, Cambissolos (EMPRESA BRASILEIRA DE PESQUISA AGROPECUÁRIA, 1984) e Argissolos (PARANÁ, 1987).

Conforme a classificação do Instituto Brasileiro de Geografia e Estatistica (1992), a formação florestal original da área de estudo é classificada como Floresta Ombrófila Mista Montana. Contudo, devido às diversas atividades antrópicas a vegetação se encontra em diferentes estágios sucessionais.

Na Figura 1 pode-se observar o uso do solo da área de estudo, com as respectivas localizações das unidades amostrais.

No primeiro semestre de 2001, o Laboratório de Inventário Florestal/UFPR realizou o inventário florestal, utilizando o método de amostragem de área fixa e o processo sistemático, no qual foram locadas e medidas 70 unidades amostrais (UAs) de $25 \mathrm{~m} \mathrm{x}$ 100 m, numeradas de 1 a 70 (Figura 2).

A quantificação de biomassa acima do solo (DAP ${ }^{3} 10,0 \mathrm{~cm}$ ) foi realizada durante o primeiro semestre de 2001 (janeiro a julho).

Nas unidaddes amostrais primárias (UAPs) (12 x $12 \mathrm{~m}$ ) (Figura 2) foram cortadas e medidas todas as árvores com $\mathrm{DAP}^{3} 10,0 \mathrm{~cm}$ para a determinação 
de biomassa acima do solo. De cada árvore foram medidas ou pesadas as seguintes variáveis: CAP (circunferência à altura do peito); altura total; altura comercial (ponto de inversão morfológica); espessura da casca; peso da massa verde da casca, da madeira do fuste, das folhas, dos galhos e da miscelânea (musgos, liquens, lianas, bromélias, orquídeas). Durante a coleta foram quantificados também flores e frutos, mas devido a pequena quantidade de material para as análises de macro e micronutrientes, estes foram agrupados no componente miscelânea.

Os materiais coletados em cada unidade amostral primária (UAP) foram pesados separadamente no campo em uma balança de gancho. Depois de pesado cada componente da árvore (madeira do fuste, casca, galhos, folhas e miscelâneas) foram retiradas amostras de aproximadamente 300 gramas. Para a amostra de madeira do fuste foram retirados dois discos de aproximadamente 5,0 cm de espessura, o primeiro a $0,5 \mathrm{~m}$ de altura acima do corte da árvore e o segundo a $0,5 \mathrm{~m}$ abaixo do ponto de inversão morfológico. Para a amostra de casca foram utilizados os mesmos discos da amostra de madeira do fuste. Em cada disco amostrado foi separada a casca da madeira do fuste. A biomassa total de casca foi estimada utilizando relações de fator de casca (WATZLAWICK, 2003). Somente foram considerados como galhos, aqueles que estavam acima do ponto de inversão morfológico. Para os galhos foram retiradas amostras em todos os diâmetros e em todas as alturas de copa. No que se refere às folhas, foram retiradas amostras na parte superior, intermediária e inferior da copa.

As amostras de cada componente foram acondicionadas e colocadas em estufa de circulação e renovação de ar forçada, para secagem à temperatura de $75^{\circ} \mathrm{C}$ por um período de 72 horas, para a determinação da massa seca (TEDESCO et al., 1995; MIYAZAWA; PAVAN; BLOCH, 1999).

Todos os indivíduos amostrados no estudo tiveram seu material vegetativo e, quando possível reprodutivo, coletados para serem submetidos aos processos de herborização, conforme as recomendações do Instituto Brasileiro de Geografia e Estatistica (1992).
O material herborizado foi identificado no Laboratório de Inventário Florestal do Departamento de Ciências Florestais da Universidade Federal do Paraná.

A determinação da biomassa por espécie e por componente foi realizada através do somatório de cada espécie amostrada e a biomassa por unidade de área (ha) foi calculada a partir da biomassa média das UAPs.

Das espécies amostradas que tinham mais de três exemplares, foram selecionados três (com maior, médio e menor DAP) e das que tinham menos de três todos foram usados para a determinação do teor de macronutrientes nos componentes da biomassa acima do solo $\left(\mathrm{DAP}^{3} 10,0 \mathrm{~cm}\right)$. Para a determinação dos macronutrientes na casca e na madeira do fuste foi utilizada a média de duas amostras.

As amostras de cada componente da biomassa foram secas em estufa de circulação e renovação de ar a $75^{\circ} \mathrm{C}$ e em seguida trituradas em moinho do tipo Wiley, passadas em peneiras de malha $1,0 \mathrm{~mm}$ (20 mesh) e armazenadas em frascos de vidros para subseqüente análise química (TEDESCO et al., 1995; MIYAZAWA; PAVAN; BLOCH, 1999).

O tecido vegetal para a determinação de N, P, S, $\mathrm{K}, \mathrm{Ca}$ e $\mathrm{Mg}$ foi submetido à digestão úmida. As análises de $\mathrm{N}$ foram feitas por titulação. $\mathrm{O} \mathrm{N}$ foi determinado pelo método Kjeldahl, chamado também de digestão sulfúrica usando o destilador de nitrogênio. As amostras de $\mathrm{K}$ foram lidas no fotômetro de chama e as amostras de $\mathrm{P}$ e $\mathrm{S}$ foram lidas no espectrofotômetro visível (VIS). No espectrofotômetro de absorção atômica (EAA) foram lidas as amostras de $\mathrm{Ca}$ e $\mathrm{Mg}$ (TEDESCO et al., 1995; MIYAZAWA; PAVAN; BLOCH, 1999).

A quantidade dos macronutrientes em kg.espécie${ }^{1}$ nos componentes da biomassa foi calculada através da multiplicação da biomassa $\left(\mathrm{kg}\right.$.espécie $\mathrm{e}^{-1}$ ) pelo teor de macronutrientes determinado para cada componente (madeira do fuste, casca, galhos, folhas e miscelânea). A soma dos valores dos macronutrientes para cada componente da biomassa forneceu a quantidade total $\left(\mathrm{Mg} \mathrm{ha}^{-1}\right)$ dos mesmos. 
Para estimar o índice de eficiência de macronutrientes (IEM acronutrientes ) para os diferentes componentes da biomassa acima do solo (DAP ${ }^{3} 10,0$ $\mathrm{cm}$ ), foi utilizada a fórmula proposta por Hansen e Baker (1979), sendo:

\section{IEMacronutrientes $=\frac{B P}{N U}$}

Onde:

$\mathrm{IEM}_{\text {acronutrientes }}=$ Índice de Eficiência de Macronutrientes

$$
\begin{aligned}
& \mathrm{BP}=\mathrm{kg} \text { de biomassa produzida } \\
& \mathrm{NU}=\mathrm{kg} \text { de nutriente utilizado }
\end{aligned}
$$

\section{Resultados e Discussão}

A quantidade de biomassa produzida em $\mathrm{kg}$ pelas espécies amostradas na Floresta Ombrófila Mista Montana por $\mathrm{kg}$ de nutriente utilizado variou, conforme pode ser observado nas Tabelas 1, 2 e 3. As variações do IEM acronutrientes $_{\text {entre as espécies }}$ também são conseqüência dos teores dos nutrientes e da biomassa produzida. De acordo com Lambers, Chapin e Pons (2000) as espécies diferem no que se refere à capacidade de absorção dos nutrientes e no uso de eficiência de utilização dos mesmos. Nesse processo, ou seja, no Índice de Eficiência de Nutrientes (IEN), dois fatores são importantes: o primeiro ligado aos fatores genéticos das espécies (diferenciações genéticas entre as espécies) e o segundo às condições climáticas (aclimatação das espécies).

As espécies, de uma maneira geral, utilizaram mais eficientemente os nutrientes para a formação da biomassa, na seguinte ordem decrescente: $\mathrm{P}>\mathrm{S}>\mathrm{Mg}$ $>\mathrm{Ca}>\mathrm{K}>\mathrm{N}$ (Tabelas 1, 2 e 3). Notam-se algumas semelhanças na ordem de IEM $_{\text {acronutrientes }}$ entre as espécies estudas com os resultados encontrados por Drumond (1996) para espécies com plantios puros e mistos e Drumond et al. (1997) em dez espécies não leguminosas da Mata Atlântica e procedências australianas de Acacia mearnsii (CALDEIRA; RONDON NETO; SCHUMACHER, 2002).
Para N, a espécie que apresentou o índice de eficiência mais alto desse nutriente para a produção de biomassa total foi Xylosma sp e para P, Mimosa scabrella. $\mathrm{O}$ menor índice de eficiência de $\mathrm{P}$ para a produção de biomassa total foi observado nas espécies Sapium glandulatum, Dicksonia sellowiana e Allophyllus edulis.

No entanto, o menor índice de eficiência de $\mathrm{N}$ para a produção de biomassa total foi observada em Allophyllus edulis, Mimosa scabella e Campomanesia xanthocarpa (Tabela 1).

Para todas as espécies, verifica-se que Xylosma sp apresentou alto índice de eficiência de $\mathrm{N}$ para a produção de biomassa do fuste, folhas e total. O N possui índice de eficiência relativamente baixa em relação aos outros macronutriente, devido aos altos teores nas folhas verdes e redistribuição interna, voltando ao solo através da serapilheira, sendo assim novamente integrado ao ciclo biogeoquímico.

Analisando-se o índice de eficiência de cada macronutriente para a produção de biomassa de cada componente, as espécies Drimys brasiliensis, Mimosa scabrella, Prunus brasiliensis, Quillaja brasiliensis e Symplocos celastrina apresentaram índice de eficiência alto de $\mathrm{P}$ na produção de biomassa do fuste em relação as demais espécies e macronutrientes na produção de biomassa total. Porém, pode-se observar na Tabela 1 que as espécies que apresentaram índice de eficiência baixo de $\mathrm{P}$ para a produção de biomassa do fuste, em ordem decrescente foram: Sapium glandulatum, Dicksonia sellowiana e Persea major.

Caldeira, Rondon Neto e Schumacher (2002) encontraram índice de eficiência alto de $\mathrm{P}$ para a produção de biomassa total acima do solo em três procedências australianas de Acacia mearnsii. Tal fato foi confirmado por Vitousek (1984), onde o P foi o único dos elementos que nas florestas tropicais apresentou uma elevada eficiência de utilização, principalmente em áreas onde este se encontra em baixos teores no solo.

Algumas espécies podem apresentar índice de 
Tabela 1. Índice de Eficiência de N e P nos componentes da biomassa acima do solo - Floresta Ombrófila Mista Montana.

\begin{tabular}{|c|c|c|c|c|c|c|}
\hline \multirow{2}{*}{ Espécie } & \multicolumn{2}{|c|}{ Fuste $^{(1)}$} & \multicolumn{2}{|c|}{ Folhas } & \multicolumn{2}{|c|}{ Total $^{(2)}$} \\
\hline & $\mathrm{N}$ & $\mathrm{P}$ & $\mathrm{N}$ & $\mathrm{P}$ & $\mathrm{N}$ & $\mathrm{P}$ \\
\hline$\overline{\text { Allophyllus edulis }}$ & 180 & 1,728 & 35 & 515 & 102 & 978 \\
\hline Araucaria angustifolia & 300 & 7,155 & 68 & 694 & 253 & 3,988 \\
\hline Calyptranthes concinna & 489 & 1,376 & 72 & 1,408 & 330 & 1,395 \\
\hline Campomanesia xanthocarpa & 146 & 4,255 & 46 & 775 & 109 & 1,734 \\
\hline Casearia decandra & 219 & 4,380 & 35 & 754 & 146 & 2,500 \\
\hline Clethra scabra & 278 & 3,705 & 43 & 617 & 204 & 2,372 \\
\hline Cupania vernalis & 285 & 3,681 & 54 & 535 & 171 & 2,285 \\
\hline Dicksonia sellowiana & 246 & 912 & 47 & 581 & 132 & 815 \\
\hline Drimys brasiliensis & 342 & 10,217 & 46 & 592 & 671 & 1,732 \\
\hline Ilex dumosa & 201 & 8,121 & 47 & 952 & 174 & 2,063 \\
\hline Ilex microdonta & 393 & 9,008 & 64 & 1,277 & 188 & 3,436 \\
\hline Ilex paraguariensis & 233 & 4,123 & 39 & 857 & 158 & 2,336 \\
\hline Ilex theezans & 670 & 4,172 & 41 & 893 & 670 & 3,114 \\
\hline Jacaranda puberula & 139 & 2,956 & 53 & 775 & 134 & 1,685 \\
\hline Lamanonia ternata & 431 & 7,484 & 69 & 1,031 & 215 & 3,830 \\
\hline Lithraea brasiliensis & 447 & 4,750 & 47 & 595 & 261 & 2,283 \\
\hline Matayba elaeagnoides & 265 & 5,233 & 39 & 518 & 225 & 4,206 \\
\hline Mimosa scabrella & 173 & 10,099 & 27 & 579 & 102 & 6,141 \\
\hline Myrcia sp & 413 & 3,703 & 89 & 1,493 & 290 & 2,627 \\
\hline Myrsine ferruginea & 268 & 4,931 & 41 & 526 & 183 & 2,404 \\
\hline Myrsine umbellata & 374 & 1,805 & 71 & 1,095 & 273 & 2,407 \\
\hline Nectandra megapotamica & 251 & 6,722 & 40 & 958 & 129 & 2,541 \\
\hline Ocotea porosa & 151 & 5,063 & 42 & 987 & 132 & 2,776 \\
\hline Ocotea puberula & 177 & 5,943 & 38 & 694 & 114 & 2,810 \\
\hline Ocotea pulchella & 271 & 6,047 & 49 & 1,105 & 144 & 2,667 \\
\hline Persea major & 225 & 967 & 59 & 1,064 & 406 & 1,213 \\
\hline Piptocarpha angustifolia & 266 & 5,561 & 35 & 752 & 169 & 3,846 \\
\hline Prunus brasiliensis & 334 & 8,273 & 36 & 1,020 & 158 & 3,306 \\
\hline Quillaja brasiliensis & 303 & 12,020 & 39 & 1,205 & 139 & 4,196 \\
\hline Sapium glandulatum & 235 & 430 & 29 & 512 & 158 & 469 \\
\hline Schinus Terebinthifolius & 217 & 3,315 & 38 & 885 & 161 & 3,020 \\
\hline Sebastiania brasiliensis & 793 & 3,125 & 51 & 952 & 658 & 2,476 \\
\hline Sebastiania commersoniana & 151 & 1,230 & 36 & 613 & 132 & 1,272 \\
\hline Sloanea lasiocoma & 246 & 2,437 & 70 & 962 & 229 & 2,129 \\
\hline Styrax leprosus & 352 & 3,837 & 54 & 680 & 202 & 2,523 \\
\hline Symplocos celastrina & 337 & 9,939 & 53 & 328 & 200 & 2,676 \\
\hline Symplocos uniflora & 353 & 4,974 & 53 & 823 & 186 & 3,742 \\
\hline Vernonia discolor & 325 & 3,090 & 30 & 346 & 230 & 2,609 \\
\hline Xylosma sp & 4,593 & 4,360 & 1,370 & 1,064 & 2,769 & 2,387 \\
\hline
\end{tabular}

Nota: (1) madeira do fuste + casca; (2) fuste + galhos + folhas.

eficiência alto de $\mathrm{P}$ e K para a produção de biomassa total, mesmo estando estabelecida em solos com baixos teores desse macronutriente. Drumond et al. (1997) evidenciaram que, ao contrário do K, Ca e $\mathrm{Mg}$, o estoque de $\mathrm{P}$ no solo ficou abaixo do valor encontrado na biomassa acima do solo de espécies da Mata Atlântica, justificando os altos valores de eficiência na utilização deste nutriente.

$\mathrm{O} \mathrm{K}$ e o $\mathrm{Ca}$ apresentaram índice de eficiência baixa na produção de biomassa (Tabela 2), exceto para Drimys brasiliensis que apresentou índice de eficiência alto de Ca para a produção de biomassa de fuste. Morais et al. (1990) também verificaram que o Eucalyptus citriodora, plantado em Viçosa, MG foi pouco eficiente na utilização de K para a produção de biomassa acima do solo. Essa afirmação também pode ser constada em algumas espécies da Mata Atlântica (DRUMOND et al., 1997) e em Acacia mearnsii (CALDEIRA; RONDON NETO; SCHUMACHER, 2002).

Em se tratando do índice de eficiência de K para a produção de biomassa total as espécies Sapium 
Tabela 2. Índice de Eficiência de K e Ca nos componentes da biomassa acima do solo - Floresta Ombrófila Mista Montana.

\begin{tabular}{|c|c|c|c|c|c|c|}
\hline \multirow{2}{*}{ Espécie } & \multicolumn{2}{|c|}{ Fuste $^{(1)}$} & \multicolumn{2}{|c|}{ Folhas } & \multicolumn{2}{|c|}{ Total $^{(2)}$} \\
\hline & $\mathrm{K}$ & $\mathrm{Ca}$ & $\mathrm{K}$ & $\mathrm{Ca}$ & $\mathrm{K}$ & $\mathrm{Ca}$ \\
\hline Allophyllus edulis & 182 & 161 & 98 & 99 & 150 & 127 \\
\hline Araucaria angustifolia & 153 & 114 & 104 & 70 & 145 & 120 \\
\hline Calyptranthes concinna & 183 & 375 & 117 & 107 & 164 & 215 \\
\hline Campomanesia xanthocarpa & 142 & 463 & 775 & 95 & 145 & 143 \\
\hline Casearia decandra & 107 & 94 & 70 & 70 & 116 & 74 \\
\hline Clethra scabra & 117 & 316 & 82 & 108 & 121 & 342 \\
\hline Cupania vernalis & 178 & 175 & 91 & 124 & 161 & 116 \\
\hline Dicksonia sellowiana & 130 & 484 & 73 & 106 & 112 & 278 \\
\hline Drimys brasiliensis & 611 & 1.549 & 110 & 256 & 176 & 386 \\
\hline Ilex dumosa & 170 & 492 & 89 & 120 & 156 & 188 \\
\hline Ilex microdonta & 193 & 140 & 143 & 85 & 163 & 84 \\
\hline Ilex paraguariensis & 158 & 279 & 62 & 125 & 136 & 232 \\
\hline Ilex theezans & 192 & 165 & 148 & 93 & 192 & 121 \\
\hline Jacaranda puberula & 186 & 494 & 128 & 139 & 169 & 272 \\
\hline Lamanonia Ternata & 149 & 191 & 163 & 62 & 133 & 104 \\
\hline Lithraea brasiliensis & 153 & 202 & 86 & 193 & 138 & 192 \\
\hline Matayba elaeagnoides & 185 & 100 & 105 & 122 & 149 & 126 \\
\hline Mimosa scabrella & 146 & 348 & 133 & 146 & 144 & 182 \\
\hline Myrcia sp & 167 & 360 & 115 & 155 & 150 & 259 \\
\hline Myrsine ferruginea & 135 & 232 & 67 & 122 & 117 & 178 \\
\hline Myrsine umbellata & 156 & 120 & 104 & 102 & 147 & 121 \\
\hline Nectandra megapotamica & 175 & 445 & 107 & 173 & 151 & 210 \\
\hline Ocotea porosa & 151 & 503 & 101 & 150 & 151 & 209 \\
\hline Ocotea puberula & 134 & 386 & 88 & 123 & 123 & 220 \\
\hline Ocotea pulchella & 147 & 180 & 106 & 123 & 148 & 153 \\
\hline Persea major & 145 & 163 & 100 & 70 & 157 & 128 \\
\hline Piptocarpha angustifolia & 146 & 880 & 103 & 276 & 133 & 674 \\
\hline Prunus brasiliensis & 682 & 515 & 123 & 218 & 253 & 312 \\
\hline Quillaja brasiliensis & 193 & 310 & 115 & 122 & 156 & 238 \\
\hline Sapium glandulatum & 125 & 202 & 44 & 88 & 107 & 177 \\
\hline Schinus Terebinthifolius & 183 & 200 & 101 & 133 & 153 & 195 \\
\hline Sebastiania brasiliensis & 183 & 163 & 137 & 81 & 173 & 136 \\
\hline Sebastiania commersoniana & 190 & 492 & 112 & 103 & 187 & 337 \\
\hline Sloanea lasiocoma & 156 & 139 & 139 & 108 & 153 & 128 \\
\hline Styrax leprosus & 132 & 278 & 170 & 86 & 144 & 180 \\
\hline Symplocos celastrina & 181 & 225 & 68 & 95 & 158 & 199 \\
\hline Symplocos uniflora & 150 & 308 & 142 & 111 & 142 & 229 \\
\hline Vernonia discolor & 149 & 462 & 39 & 169 & 134 & 568 \\
\hline Xylosma sp & 141 & 213 & 118 & 53 & 153 & 146 \\
\hline
\end{tabular}

Nota: (1) madeira do fuste + casca; (2) fuste + galhos + folhas.

glandulatum e Prunus brasiliensis, apresentaram, respectivamente, menor e maior índice. No que se refere ao índice de eficiência de $\mathrm{Ca}$, Casearia decandra apresentou índice baixo para a produção de biomassa total e Piptocarpha angustifolia e Vernonia discolor índice alto.

Para algumas espécies, o Ca foi o elemento com índice de eficiência baixo para a produção de biomassa do fuste, quando comparado aos demais componentes da biomassa. Isso talvez seja devido ao elevado teor de Ca na casca, que se deve em parte a imobilização desse macronutriente no floema, principalmente na forma de oxalato de cálcio, fato esse também observado por Caldeira, Rondon Neto e Schumacher (2002) em procedências de Acacia mearnsii, no Rio Grande do Sul.

Na Tabela 3, pode-se observar que as espécies, Myrsine ferruginea, Nectandra megapotamica e Vernonia discolor apresentaram índice de eficiência alta Mg para a produção de biomassa total. Porém, somente quatro espécies, Sloanea lasiocoma, Matayba elaeagnoides, Prunus brasiliensis e 
Lamanonia ternata, apresentaram índice de eficiência alta de $\mathrm{S}$ para a produção de biomassa total. De acordo com Caldeira, Rondon Neto e Schumacher (2002), depois do P, o S foi o nutriente mais eficientemente utilizado pelas três procedências de Acacia mearnsii para produção de biomassa, principalmente na produção de madeira do fuste.

Tabela 3. Índice de Eficiência de Mg e S nos componentes da biomassa acima do solo - Floresta Ombrófila Mista Montana.

\begin{tabular}{|c|c|c|c|c|c|c|}
\hline \multirow{2}{*}{ Espécie } & \multicolumn{2}{|c|}{ Fuste $^{(1)}$} & \multicolumn{2}{|c|}{ Folhas } & \multicolumn{2}{|c|}{ Total $^{(2)}$} \\
\hline & $\mathrm{Mg}$ & $\mathrm{S}$ & $\mathrm{Mg}$ & $\mathrm{S}$ & $\mathrm{Mg}$ & $\mathrm{S}$ \\
\hline Allophyllus edulis & 734 & 1,671 & 180 & 312 & 633 & 766 \\
\hline Araucaria angustifolia & 1,167 & 1,020 & 266 & 704 & 878 & 896 \\
\hline Calyptranthes concinna & 6,126 & 251 & 377 & 358 & 1,736 & 295 \\
\hline Campomanesia xanthocarpa & 697 & 657 & 518 & 481 & 695 & 667 \\
\hline Casearia decandra & 333 & 700 & 251 & 521 & 376 & 642 \\
\hline Clethra scabra & 434 & 735 & 241 & 508 & 503 & 826 \\
\hline Cupania vernalis & 814 & 2,156 & 192 & 305 & 809 & 1,462 \\
\hline Dicksonia sellowiana & 471 & 777 & 261 & 543 & 404 & 713 \\
\hline Drimys brasiliensis & 377 & 1,663 & 308 & 917 & 534 & 991 \\
\hline Ilex dumosa & 613 & 1,996 & 146 & 597 & 512 & 1,173 \\
\hline Ilex microdonta & 840 & 2,322 & 197 & 591 & 649 & 1,432 \\
\hline Ilex paraguariensis & 697 & 1,644 & 203 & 568 & 613 & 1,467 \\
\hline Ilex theezans & 421 & 1,174 & 125 & 444 & 401 & 1,032 \\
\hline Jacaranda puberula & 1,606 & 2,218 & 301 & 709 & 922 & 1,027 \\
\hline Lamanonia ternata & 492 & 3,853 & 272 & 709 & 427 & 2,199 \\
\hline Lithraea brasiliensis & 1,299 & 2,954 & 559 & 637 & 1,099 & 1,611 \\
\hline Matayba elaeagnoides & 587 & 2,764 & 176 & 386 & 653 & 2,577 \\
\hline Mimosa scabrella & 1,918 & 2,395 & 665 & 619 & 1,347 & 1,605 \\
\hline Myrcia sp & 1,222 & 2,674 & 662 & 816 & 1,547 & 937 \\
\hline Myrsine ferruginea & 3,260 & 353 & 713 & 406 & 2,271 & 410 \\
\hline Myrsine umbellata & 2,273 & 2,290 & 385 & 488 & 1,482 & 1,182 \\
\hline Nectandra megapotamica & 5,098 & 1,609 & 620 & 508 & 2,285 & 1,582 \\
\hline Ocotea porosa & 7,764 & 530 & 711 & 459 & 1,913 & 617 \\
\hline Ocotea puberula & 207 & 1,953 & 532 & 508 & 484 & 1,661 \\
\hline Ocotea pulchella & 1,551 & 548 & 418 & 472 & 1,269 & 754 \\
\hline Persea major & 3,658 & 1,209 & 435 & 465 & 1,192 & 1,499 \\
\hline Piptocarpha angustifolia & 2,546 & 1,516 & 385 & 451 & 1,604 & 1,023 \\
\hline Prunus brasiliensis & 2,765 & 2,010 & 265 & 1,124 & 1,404 & 2,206 \\
\hline Quillaja brasiliensis & 3,103 & 684 & 518 & 444 & 1,433 & 930 \\
\hline Sapium glandulatum & 1,415 & 819 & 243 & 583 & 1,044 & 703 \\
\hline Schinus terebinthifolius & 1,185 & 848 & 552 & 483 & 1,064 & 883 \\
\hline Sebastiania brasiliensis & 1,001 & 2,006 & 252 & 658 & 830 & 1,883 \\
\hline Sebastiania commersoniana & 950 & 2,382 & 227 & 1,923 & 881 & 2,321 \\
\hline Sloanea lasiocoma & 1,081 & 3,043 & 397 & 581 & 1,122 & 2,621 \\
\hline Styrax leprosus & 1,501 & 2,949 & 575 & 680 & 959 & 1,670 \\
\hline Symplocos celastrina & 3,233 & 2,529 & 476 & 218 & 1,791 & 1,573 \\
\hline Symplocos uniflora & 2,081 & 615 & 244 & 385 & 1,591 & 652 \\
\hline Vernonia discolor & 3,602 & 1,479 & 538 & 364 & 2,129 & 1,917 \\
\hline Xylosma sp & 2,283 & 1,547 & 345 & 402 & 1,336 & 1,565 \\
\hline
\end{tabular}

Nota: (1) madeira do fuste + casca; (2) fuste + galhos + folhas.

Para a produção de biomassa do fuste somente duas espécies apresentam índice de eficiência alta de $\mathrm{Mg}$ e $\mathrm{S}$ e para a produção de biomassa de folhas, também duas espécies, Sebastiania commersoniana e Prunus brasiliensis, de Ca e Mg para a produção de biomassa total. apresentaram índice de eficiência alta de S.
Em síntese, as Tabelas 1, 2 e 3 mostram que Prunus brasiliensis apresentou alto índice de eficiência de $\mathrm{K}$ e $\mathrm{S}$ para a produção de biomassa total e Vernonia discolor alto índice de eficiência 
Segundo Drumond (1996) a eficiência de uso de nutrientes varia com a espécie e com o tipo de vegetação. As espécies da mata natural consomem mais nutrientes do que as espécies de plantios puros. Isso, possivelmente, de acordo com Drumond (1996) ocorre em virtude da maior disponibilidade dos nutrientes no solo, decorrente de uma ciclagem e liberação mais uniforme dos mesmos.

As diferenças no IEM acronutrientes $_{\text {, entre as espécies }}$ estudadas podem ser devidas ao reflexo de uma adaptação às perdas anuais de nutrientes e ao aumento da reutilização dos mesmos. Portanto, uma menor perda dos elementos que formam a serapilheira, principalmente o componente folha, e a alta redistribuição dos nutrientes antes da derrubada das folhas são estratégias que as espécies podem utilizar para aumentar a conservação dos nutrientes nos componentes das árvores.

Cabe ressaltar que as diferenças de eficiência no uso de micronutrientes entre as espécies do presente estudo podem ser também devido o tempo de coletas (janeiro a julho) nas amostras. Ne sentido, a literura mostra que os teores de nutrientes na biomassa são em função de vários fatores, entre eles pragas e enfermidades, idade das árvores e das folhas, posição na copa, estação do ano, qualidade do sítio, procedência, variação conforme o elemento, características nutricionais de cada espécie, disponibilidade de nutrientes no solo, componente a ser analisado (BELLOTE; SILVA, 2000).

Dos fatores citados com influenciam no teor de nutrientes na biomassa das árvores, dois merecem destaque: a idade do material amostrado e a espécie. De acordo com Bellote e Silva (2000) a idade do material amostrado se refere à idade fisiológica das folhas, onde o teor de nutrientes nestes órgãos depende, principalmente, do estádio fisiológico e da oferta de nutrientes no solo.

A idade fisiológica das folhas afeta o teor de nutrientes em função da redistribuição de determinados nutrientes móveis para outros órgãos como folhas novas, órgãos de reserva, frutos e regiões de crescimento, antes da abscisão. Portanto, está é uma maneira pela qual a planta conserva parte dos nutrientes absorvidos (MILLER, 1984). Aproximadamente 60 a $85 \%$ da maioria dos nutrientes podem ser conservados desta maneira, com exceção do $\mathrm{B}$ e do $\mathrm{Ca}$ por serem imóveis nas plantas (MALAVOLTA, 1980).

Em síntese pode-se dizer que é bem provável que as diferenças de eficiência no uso de micronutrientes (Tabelas 1, 2 e 3) sejam bem mais evidenciadas nas folhas, brotações e tecidos corticais devido serem órgãos metabolicamnete mais ativos das plantas.

\section{Conclusões}

Os índices de eficiência de macronutrientes entre as espécies arbóreas, bem como entre os componentes da biomassa acima do solo (fuste $=$ madeira do fuste + casca; folhas e total $=$ fuste + galhos + folhas) variaram.

As espécies que apresentaram alto índice de eficiência de macronutrientes para a produção de biomassa de madeira do fuste foram as mesmas que apresentrama alto índice de eficiência de macronutrientes para a produção de componentes lenhosos (fuste + galhos), exceto Myrsine ferruginea; Schinus terebinthifolius e Calyptranthes concinna.

\section{Agradecimentos}

Os autores agradecem ao Dr. Prof ${ }^{\circ}$ Carlos Roberto Sanquetta DCF/UFPR, pela oportunidade de participar do Projeto Ecólogico de Longa Duração - PELD Site 9 Bioma Floresta de Araucária e suas Transições e pelo auxílio financeiro, bem como às Industrias Pedro N. Pizzato Ltda, pelo apoio institucional a todos os seus funcionários. 


\section{Referências}

BELLOTE, A. F. J.; SILVA, H. D. Técnicas de amostragem e avaliações nutricionais em plantios de Eucalyptus spp. In: GONÇALVES, J. L. M.; BENEDETTI, V. (Ed.) Nutrição e fertilização florestal. Piracicaba: ESALQ/USP, 2000. p.105-133.

BLAIR, G. Nutrient efficiency: what do we really mean?. genetic aspects of plant mineral nutrition. Boston: Kluwer Academic, 1993. p.205-213.

CALDEIRA, M. V. W.; RONDON NETO, R. M.; SCHUMACHER, M. V. Avaliação da eficiência nutricional de três procedências australianas de acácia-negra (Acacia mearnsii De Wild.). Revista Árvore, Viçosa, v.26, n.5, p.615-620, 2002.

CALDEIRA, M. V. W.; RONDON NETO, R. M.; SCHUMACHER, M. V. Eficiência do uso de micronutrientes e sódio em três procedências de acácianegra (Acacia mearnsii De Wild.). Revista Árvore, Viçosa, v.28, n.1, p.39-47, 2004.

CAMARGO, J. B. Geografia física, humana e econômica do Paraná. 2. ed. Paranavaí: Chichetec, 1998.

DRUMOND, M. A. Alterações fitossociológicas e edáficas decorrentes de modificações da cobertura vegetal na Mata Atlântica, região do médio Rio Doce, MG. Viçosa, MG. 1996. Tese (Doutorado em Ciência do Solo) - Universidade Federal de Viçosa, Viçosa.

DRUMOND, M. A.; BARROS, N. F.; SOUZA, A. L.; SILVA, A. F.; TEIXEIRA, J. L.. Composição mineral e demanda nutricional de espécies florestais da Mata Atlântica. Revista Árvore, Viçosa, v.21, n.1, p.1-10, 1997.

DRUMOND, M. A.; POGGIANI, F. Distribuição da biomassa e dos nutrientes em plantações puras e consorciadas de Liquidambar styraciflua e Pinus caribaea hondurensis. In: CONGRESSO FLORESTAL BRASILEIRO, 7., 1993, Curitiba. Anais... Curitiba: SBS, 1993. p.234-239.

EMPRESA BRASILEIRA DE PESQUISA AGROPECUÁRIA-Centro Nacional de Pesquisa de Solos. Sistema brasileiro de classificação de solos. Rio de Janeiro: Embrapa Solos, 1999.

Levantamento de reconhecimento dos solos do Estado do Paraná. Londrina: EMBRAPA-SNLCS/ SUDESUL / IAPAR, 1984. (Boletim de Pesquisa, 27).

FURLANI, A. M. C.; CLARK, R. B.; MARANVILLE, J. W.; ROSS, W. M. Sorghum genotype differences in phosphorus uptake, phosphorus efficiency, phosphorus mobilization and utilization. Journal of Plant Nutrition, New York, v.7, n.7, p.1113-1126, 1984.
GONÇALVES, J. L. M.; KAGEYAMA, P. Y.; FREIXÊDAS, V. M.; GONÇALVES, J. C.; GERES, W. L. A. capacidade de absorção e eficiência nutricional de algumas espécies arbóreas tropicais. In: CONGRESSO NACIONAL SOBRE ESSÊNCIAS NATIVAS: CONSERVAÇÃO DA BIODIVERSIDADE, 2., 1992. São Paulo. Anais... São Paulo: Instituto Florestal, 1992. p.463-469.

HANSEN, E. A.; BAKER, J. B. Biomass and nutrient removal in short rotation intensively cultured plantations. Thompsomville:American Poplars Council, 1979.

INSTITUTO AGRONÔMICO DO PARANÁ. Cartas climáticas básicas do Estado do Paraná. Londrina: IAPAR, 1994. (Documentos; 18).

INSTITUTO BRASILEIRO DE GEOGRAFIA E ESTATISTICA. Manual técnico da vegetação brasileira. Rio de Janeiro: IBGE, 1992.

LAMBERS, H.; CHAPIN III, F. S.; PONS, T. L. Plant physiological ecology. New York: Springer-Verlag, 2000.

LIMA, W.P. Impacto ambiental do eucalipto. 2. ed. São Paulo: Ed. da USP, 1993.

MALAVOLTA, E. Elementos da nutrição mineral de plantas. São Paulo: Ceres, 1980.

MILLER, H. G. Dynamic of nutrient cycling in plantations ecosystems. In: Nutrition of plantation forest. London: Academic, 1984. p.53-78.

MIYAZAWA, M.; PAVAN, M. A.; BLOCH, M. Análises químicas de tecido vegetal. In: SILVA, F. C. (Ed). Manual de análises químicas de solos, plantas e fertilizantes. Brasília: Embrapa Solos, 1999. (Comunicação para Transferência de Tecnologia). p.171-223.

MORAIS, E. J.; BARROS, N. F.; NOVAIS, R. F.; BRANDI, R. M. Biomassa e eficiência nutricional de espécies de eucalipto em duas regiões bioclimáticas de Minas Gerais. Revista Brasileira de Ciência do Solo, Campinas, v. 14, p. 353-362, 1990.

NEGI, J. D. S.; SHARMA, D. C. Distribution of nutrient in ages series of Eucalyptus globules plantations in Tamil Nadu. Indian Forester, Dehra Dun, v.110, n.9, p.944-953, 1984.

PARANÁ. Secretária de Estado de Agricultura e Abastecimento, Instituto de Terras, Cartografia e Florestas. Atlas do Estado do Paraná. Curitiba, 1987.

PEREIRA, A.R.; BARROS, N. F; ANDRADE, D.C.; CAMPOS, P. T. A. Concentração e distribuição de nutrientes em Eucalyptus grandis em função da idade, cultivado na região do cerrado. Brasil Florestal, Brasília, V.8, n.59, p.27-38, 1984. 
SCHUMACHER, M. V. Naehrstoffkreislauf in verschiedenen Bestaeden von Eucalyptus saligna (Smith), Eucalyptus dunnii (Maiden) und Eucalyptus globulus (Labillardière) in Rio Grande do Sul, Brasilien. 1995. Tese (Doutorado em Ecologia e Nutrição Florestal) - Universitäet für Bodenkultur, Viena.

TEDESCO, M.J.; GIANELLO, C.; BISSANI, C. A.; BOHNEN, H.; VOLKWEISS, S. J. Análise de solos, plantas e outros materiais. Porto Alegre: Ed. UFRG, 1995. (Boletim Técnico; 5).
VITOUSEK, P.M. Litterfall, nutrient cycling and nutrient limitation in tropical forests. Ecology, Durham, v.65, n.1, p.258-298, 1984.

WATZLAWICK, L. F. Estimativa de biomassa e carbono em Floresta Ombrófila Mista e plantações florestais a partir de dados de imagens do satélite IKONOS II. 2003. Tese (Doutorado em Ciências Florestais) - Universidade Federal do Paraná, Curitiba. 